\title{
Editorial
}

\section{Newer Viral Infection in Bangladesh--are We Prepared to Face Them?}

\author{
ME Karim
}

Despite an elaborate planning and measures to tackle microbes, emerging infectious diseases remain a crucial global challenge. Emerging infections can be defined as "infections that have newly appeared in a population or have existed previously but are rapidly increasing in incidence or geographic range"1. Infectious diseases account for $20 \%$ of global mortality, with viral diseases causing about one third of these deaths ${ }^{2}$. In addition to the rapidly changing social, environmental and behavioural patterns observed among the population of Bangladesh in the face of rapid urbanization and everincreasing global travel and trade, there is also a dramatic rise in the spectrum of infectious diseases ${ }^{2}$. The unprecedented growth of the population sharing a fragile ecology, close interactions of humans and animals, large urban dwellers living in unhygienic conditions, highly vulnerable food security and safety along with the adversities of natural disasters and global warming, make Bangladesh increasingly vulnerable to the public health threats of emerging and re-emerging diseases (EIDs) and antibiotic resistance ${ }^{3}$. Emergence/ re-emergence of several viral infections have been reported from Bangladesh in the past few decades ${ }^{4}$. They include infection due to Nipah, Severe acute respiratory syndrome (SARS), Influenza H5N1, Influenza H1N1, Influenza H7N9, Chikungunya, Human Enterovirus-71, Dengue, Japanese Encephalitis, Severe fever with thrombocytopenia syndrome (SFTS), Middle East Respiratory Syndrome Corona Virus (MERS CoV) and Zika virus infection. This increase is a result of both the increase in the rate of emerging zoonotic infections across the globe and our enhanced ability to detect and identify agents. When considering the threat posed by emerging viruses, it is useful to divide them into three categories: newly emerging viruses, reemerging viruses, and viruses deliberately spread by bioterrorists. Recognizing this urgent need to respond to the rising threats of highly infectious viral diseases and to comply with the International Health Regulations (2005) by WHO, Bangladesh has already taken several steps to address a number of issues for maintaining a sustainable animal, human and

1. Prof. Md. Enamul Karim, Professor \& Head, Department of Medicine, Dhaka Medical College, Dhaka, Bangladesh

\footnotetext{
Address of correspondence :

Prof. Md. Enamul Karim, Professor \& Head, Department of Medicine, Dhaka Medical College, Dhaka, Bangladesh.

Mob: +88-01711120874.

Email:drenamul_karim@yahoo.com
}

eco-health, including proper waste disposal in laboratories and industries, hygienic animal slaughtering practices in wet markets, and monitoring of antibacterial resistance and residual effect ${ }^{5-7}$. Genomic sequencing has facilitated identification of viruses, other advances are helping to diagnose viral illnesses. Specifcally, polymerase chain reaction (PCR), the nucleic acid amplification technology initially developed in 1983, is now more rapid and less cumbersome, allowing for deployment in outbreaks, even in resource-poor settings ${ }^{8}$. New technologies have expanded the sensitivity and scope of our detection and diagnostic capability ${ }^{9}$. However, a pathogen may still go undetected if it does not cause a significant disease outbreak. Creating increased awareness and training of clinical microbiologists/virologists for identification of new/emerging pathogens, and prompt reporting and management of outbreaks is essential to tackle the threat posed by emerging/re-emerging infection.

\section{References :}

1. Morse SS, Schluederberg A. Emerging viruses: the evolution of viruses and viral diseases. J Infect Dis. 1990; 162:1-7.

2. Friel $\mathrm{S}$ et al. Global health equity and climate stabilisation: a common agenda. Lancet 2008; 372(9650):1677-83.

3. Morse S. Factors in the emergence of infectious diseases. Emerging Infectious Diseases 1995; 1:7- 15

4. Chua KB, Goh KJ, Wong KT, et al. Fatal encephalitis due to Nipah virus among pig-farmers in Malaysia. Lancet 1999; 354:1257-9.

5. Marshall BJ, Warren JR. Unidentified curved bacilli in the stomach of patients with gastric and peptic ulceration. Lancet 1984; i:1311-5

6. Rahman M. Emerging Infectious Diseases (EIDs): One Health Approach to Combat MERS-CoV, Ebola and Nipah in Bangladesh. 8th One Health Bangladesh Conference; 2015.

7. Emily SG. Ecological Determinants of Nipah Virus Risk in Bangladesh: The Convergence of People, Bats, Trees and a Tasty Drink. 8th One Health Bangladesh Conference; 2015.

8. Grijalva CG, Nuorti JP, Griffin MR. Antibiotic prescription rates for acute respiratory tract infections in US ambulatory settings. JAMA 2009; 302:758-66.

9. Esposito S, Marchisio P, Morelli P, Crovari P, Principi N. Effect of a rapid influenza diagnosis. Arch Dis Child. 2003; 88:525-6. 